\title{
O HOMESCHOOLING E AS DISCUSSÕES ENTRE A NECESSIDADE FAMILIAR E A LEGISLAÇÃO
}

\author{
Prof. Dr. Gabriel César Dias Lopes, PhD
}

\section{RESUMO}

Este artigo discute, a importância e as implicações da educação domiciliar como um ensino individualizado para o desenvolvimento e aprendizagem da criança. Nele é explicitado o motivo pelo qual as famílias optam por esse método de ensino. No Brasil era um assunto que pouco se discutia, mais a cada dia vemos que essa barreira do silêncio está sendo quebrada e o tema tornou-se mais evidente, tanto que, mesmo com as dificuldades, já se estima um número elevado de adeptos em todo o país. Também é apresentado e esclarecido o significado de educar os filhos em casa, como isso ocorre, e a situação jurídica brasileira diante da questão, análises e outros aspectos que envolve a educação domiciliar, como a importância da família para o desenvolvimento cognitivo da criança e as discussões e impasses acerca da socialização escolar.

Palavras Chave: Educação Domiciliar, Legislação, Aprendizagem, Socialização. 


\section{ABSTRACT}

This article discusses, the importance and implications of homeschooling as an individualized teaching for the child's development and learning. It explains why families choose this teaching method. In Brazil it was a subject that was little discussed, but every day we see that this barrier of silence is being broken and the theme has become more evident, so much so that, despite the difficulties, a high number of supporters is already estimated throughout the country. It also presents and clarifies the meaning of educating children at home, how it occurs, and the Brazilian legal situation regarding the issue, analyzes and other aspects involving home education, such as the importance of the family for the child's cognitive development and the discussions and impasses about school socialization.

Keywords: Homeschooling, Legislation, Learning, Socialization

*Gabriel César Dias Lopes é Ph.D é Graduado em: Teologia, Direito, Administração e Recursos Humanos, MBA em Marketing e Gestão Estratégica, Pós-Graduado em Psicanálise, Coordenador do Curso de Pós Graduação Lato Sensu em Psicanálise Clinica da FABIC, Mestre em Educação, Mestre em Administração, Doutor em Educação e um Ph.D em Psicanálise. Membro da International Special Court of Arbitration and Human Rights - Registro: ISCAHRGCDL-17/11n2016, Membro da Comissão Científica da Olympus Intellectual Center, Atenas (Grecia), Presidente da LUI - Logos University International.

\section{INTRODUÇÃO}

A educação domiciliar é um modelo educacional, para as famílias que buscam um método de ensino voltado para o ensino individualizado, ministrado por um professor diplomado ou os próprios pais. O ensino doméstico é legalizado em vários países. No Brasil ainda é proibido, mas já existe um projeto de Lei no Senado Federal, à espera de aprovação, para que a modalidade seja legalizada. 
Antes da criação da institucionalização do ensino, a maioria da educação em todo o mundo decorria no seio familiar ou comunidade e, apenas uma pequena proporção da população se deslocava para a escola ou empregava tutores. Atualmente é obrigatória aos pais a matricula dos filhos na educação básica a partir dos quatro anos de idade, do que decorre a proibição do ensino doméstico.

O ensino doméstico é sempre a partir de casa e os tutores ou professores são sempre na maioria das vezes os pessoas da própria família, o currículo pode ser dirigido, sendo bastante semelhante ao existente nas escolas , ou pais tutores podem seguir um currículo livre, permitindo a criança que aprenda de forma auto didática, assim, a educação domiciliar exige mais dos pais, que passam a supervisionar intensamente o ensino aprendizagem de seus filhos.

As motivações para educar uma criança em casa podem ser a seguintes:

- Perigos do ambiente escolar (aliciamento para o consumo de drogas, abusos por diversos, bullying);

- Proteção contra desrespeito a valores morais, culturais, religiosos ou ideológicos;

- Flexibilidade na aplicação de conteúdos curricular;

- Possibilidade de experimentar modelos educativos alternativos, tais como o ensino adaptado ao desenvolvimento particular da criança;

- Flexibilidade de horários;

Embora as críticas sejam levantadas principalmente quanto ao aspecto da sociabilização da criança educada em casa, pesquisas feitas nos EUA, mostraram que o número de crianças socialmente privadas é bem pequeno e que a sociabilidade se dá por participação comunitária, social e política. A justificativa desse artigo reside na constatação de que nosso sistema educacional tem demonstrado baixa qualidade em desenvolvimento educacional e portanto a a educação familiar pode ser além de uma alternativa viável, uma opção para os pais e não ser vista sob o prisma da ilegalidade, e devendo ser levado em consideração as especificidades e os fatores que levam essas famílias a optarem pela educação domiciliar. 
Nesse sentido, o objetivo principal desse artigo é apresentar da educação domiciliar como alternativa educacional de ensino possível e alternativa enquanto forma de ensino, que além de possibilitar a criança um ensino individualizado, voltado às suas especificidades, mais integrado a família e diversificado também com a possibilidade de alcançar um nível acadêmico melhor e livre. Nesse sentido nos deteremos em analisar dois pontos relevantes que são o desenvolvimento acadêmico das crianças do ensino domiciliar, e a socialização dessas crianças com a família e ao mesmo a ausência dessa mesma socialização via escola.

A metodologia aqui utilizada foi baseada em pesquisas bibliográficas em sites, artigos, revistas eletrônicas etc., enfatizando, porém, a exiguidade de produções acadêmicas acerca dele.

\section{EDUCAÇÃO DOMICILIAR OU HOMESCOOLING, O QUE É E COMO FUNCIONA?}

Também conhecida pelo termo inglês homescooling a educação domiciliar tem como objetivo educar em casa crianças, adolescentes e até mesmo adultos conforme seu ritmo e interesse. Antes de se tornar uma modalidade de ensino e aprendizado, foi um movimento de reforma educacional realizado na década de 70 por John Holt, professor norte americano que reivindicava a necessidade da humanização e informalidade das escolas, onde as crianças pudessem se desenvolver de acordo com a sua curiosidade.

Desse conjunto de ideias surge o "UNSCOOLING" ou desescolarização que apregoava que a aprendizagem deveria ocorrer de forma natural e espontânea fora do ambiente escolar na desescolarização, a criança tinha a liberdade de decidir quais atividade educativa realizaria tai como: contato com a natureza, treinar abilidades na cozinha, ir a biblioteca ou simplesmente ler ao ar livre.

Os argumentos de JOHN HOLT inspiraram os primeiros homescooling, e tempos depois grupos de pais passaram a educar seus filhos em casa. A partir da 
década de 80 grupos evangélicos, passaram a aderir ao ensino doméstico pelo fato de poderem ensinar as crianças conteúdos escolares de acordo com seus princípios cristãs. Apesar do homescooling ter tido o seu início nos Estados Unidos a prática do ensino doméstico tem sido difundida no mundo todo países como: Alemanha, Japão, Hungria, México, Taiwan, Canadá, Espanha, França, Itália, China, Egito, Noruega etc.

\subsection{O SURGIMENTO DO HOMESCOOLING NO BRASIL}

No Brasil a educação domiciliar surgiu como uma modalidade de educação com o objetivo de dar aos pais a oportunidade de flexibilizar o conteúdo escolar. Entretanto, muitas famílias aderiram esse modelo de educação como forma definitiva de ensino.

Esse modelo de educação não é regulamentado, e, ao contrário de outros países, no Brasil é proibido sua prática. Mesmo sendo uma ação irregular, pesquisas demonstram que sua prática vem crescendo junto ao número de adeptos, observando-se que existem famílias que escondem a substituição da escola institucionalizada pela educação administrada em casa pelos próprios pais ou professor contratados.Já existe no senado um projeto de lei que espera sua aprovação, projetos esses de dois deputados o primeiro do deputado Lincoln Portela e o outro do deputado Eduardo Bolsonaro, apesar do crescente interesse pelo tema, especialistas acreditam que a aprovação ainda está longe de acontecer.

A Associação Nacional de Educação Domiciliar luta há anos para que a educação domiciliar seja reconhecida e regulamentada em um sistema que envolva Estado e Família. Segundo a ANED hoje são 18 famílias com problemas na justiça por manterem seus filhos longe da escola, e todas torcem para que o Supremo Tribunal Federal resolva essa questão. 


\subsection{LEGISLAÇÃO BRASILEIRA X HOMESCHOOLING}

A atual legislação brasileira, tanto no que tange à Constituição Federal, quanto à Lei de Diretrizes e Base da Educação Nacional ( LDB) e ao Estatuto da Criança e do Adolescente, são contrárias à educação domiciliar e afirmam que a mesma não é regulamentada nem reconhecida pelo Ministério da Educação Brasileira o MEC e fere os princípios das mesmas.

De acordo com a LDB é dever dos pais ou responsável matricular as crianças na educação básica de ensino a partir dos 4 anos. O Estatuto da Criança e do Adolescente no artigo 53 diz: Tanto a criança quanto o adolescente têm direito a educação, visando o pleno desenvolvimento de suas pessoas, preparo para o exercício da cidadania e qualificação para o trabalho. A Constituição Federal também estipula a obrigação de matricular filhos e pupilos na rede regular de ensino.

Segundo nota divulgada no jornal O Globo em 2015, o procurador geral da república, Rodrigo Janot, opinou contra o pedido de uma família gaúcha acerca da educação domiciliar e argumentou que o artigo 205 da Constituição Federal garante a educação como direito de todos e dever do estado e da família, mas não abre brecha para o ensino doméstico. Para Janot a escola e o espaço de convívio de diferenças e aprendizado coletivo.

\subsection{POR QUE OPTAR POR UMA EDUCAÇÃO DOMICILIAR?}

Muitas famílias acabam aderindo à educação domiciliar por inúmeras razões, essas geradas pela incidência de agressões e discriminações de ordem de gênero, etnia, sexualidade, bullying, dificuldade de aprendizado, aversão social,etc. De acordo com o diretor jurídico da Associação Nacional de Educação Domiciliar, Alexandre Magno Fernandes Moreira, a educação é constitucional e está alinhada com convenções internacionais apesar de normativas brasileiras tornarem obrigatório e compulsória a obrigatoriedade dos pais e/ou responsáveis matricularem os filhos nas instituições escolares. 
Pesquisas feitas pelo jornal O Globo, mostram que a quantidade de cidades e famílias que já aderiram a esse tipo de educação vem crescendo, e, em São Paulo reside o maior número de adeptos com 583 famílias, Minas Gerais 380 famílias, Rio Grande do Sul 363 famílias, Santa Catarina 336 e Bahia com 325 famílias. Todas essas famílias buscam a regulamentação do ensino domiciliar.

Entendem que os filhos aprendem satisfatoriamente com um ensino mais individualizado pois, tem a atenção voltada toda para eles, diferente de uma sala de aula onde uma única professora precisa dar atenção para um número maior de alunos , na educação domiciliar o aluno aprende de acordo com seu próprio ritmo por que ele vai está livre para escolher o que quer estudar e como estudar, com isso seu empenho será melhor e se sentira mais motivado a aprender a partir da sua própria curiosidade.

Está muito próxima daquilo que entendemos por Educação Ativa.

Levando em conta o que foi apresentado e o ponto de vista dos dois lados em questão fica bem claro que ambos têm o mesmo objetivo educar as crianças, porém formas diferentes. A legislação brasileira defende que, para uma criança estudar em um ambiente onde possa socializar com outras crianças é melhor para seu desenvolvimento educacional e estará mais preparada para conviver em sociedade. Já a educação domiciliar prega que uma educação de qualidade pode ser desenvolvida em casa e que a criança aprendera mais com a atenção toda voltada para si, respeitando seus próprios limites isso fará com que elas se sintam motivadas a aprender.

Em observação de ambos os aspectos entende-se que a educação pode acontecer tanto no ambiente escolar institucionalizado, quanto como em casa, o que muda é a metodologia que será aplicada , o que será ensinado a essas crianças de modo que elas venham se sentir motivadas a aprender e adquirir o conhecimento para que possam interagir com a sociedade a qual fará parte. Entende-se aqui que essa visão tem absolutamente à visão histórica de educação bem como os pressupostos sócio-políticos da época em questão. 


\subsection{EVOLUÇÃO HISTÓRICA DO CONCEITO DE EDUCAÇÃO}

A educação é vista como uma forma de transmissão de conhecimento, uma das formas onde é mais aplicada é na escola com todo aquele padrão de ensino: professor, sala de aula e alunos, realidade essa que nem sempre existiu, uma das primeiras formas de educação, foi sem dúvida a educação transmitida em casa, onde só, os filhos dos senhores tinha direito a educação ministrada em domicilio por um professor contratado, para ensinar apenas aquela criança.

Com a Era Moderna foram surgindo as primeiras escolas, ainda voltada para as crianças de classe alta, hoje essa realidade é diferente, pois todos tem acesso a escola porque existe até então leis que asseguram esse acesso à educação.

O artigo 205 da Constituição Federal (Brasil, 2007) dispõe que: A educação é direito de todos e dever do estado e da família e incentivada com a colaboração da sociedade, visando o pleno desenvolvimento da pessoa e seu preparo para a cidadania e qualificação para o trabalho.

A mesma Constituição dispõe que a criança é um ser social que nasce com capacidade afetiva, emocional e cognitivas. Ampliando suas relações sociais, interações e formas de comunicações. Podendo aprender nas trocas sociais com diferentes crianças e adultos, cuja concepção e compreensão da realidade são diversas. (Brasil, 1998, p.21, vol .2 .

Entendendo que o conceito de educação nada mais é que uma transmissão de conhecimento, conhecimento esse que pode ser transmitido em qualquer lugar, como já foi citado anteriormente um dos lugares onde era transmitida essa educação era em casa, sim em casa. Essa antiga prática está sendo readquirida atualmente por algumas famílias, alegando uma educação de qualidade, porem tem recebido muitas posições contra principalmente das leis que defende a educação passada em sala de aula transmitida pelo professor, defendendo a tese de que na escola a criança pode socializar com o todo principalmente com outras crianças da mesma idade.

Porém partindo do pressuposto defendido por nós que a educação é ativa e 
participativa ela pode e deve ser concebida, realizada a partir do próprio sujeito e , portanto, a proposta de homeschooling tendo o lar como seu centro é plenamente aceitável e possível, pois sendo a educação o maior e mais importante bem, que qualquer ser humano possa ter e proporcionar a outrem, a educação primeira dada pela família, onde os valores são solidificados, pode e deve ser prorrogado ultrapassando (não diminuindo) à educação proporcionada pelas instituições, porém dando à família e ao individuo o direito da escolha.

\section{A FAMILIA E O DESENVOLVIMENTO AFETIVO E COGNITIVO DA CRIANÇA}

A família é de suma importância para o desenvolvimento afetivo e cognitivo da criança, pois a criança reflete tudo aquilo que aprende em casa. Se é tratada com amor, carinho e compreensão, com certeza transmitirá essa afetividade ao seu entorno. Dessa forma a família é o alicerce de desenvolvimento na vida da criança.

Segundo Wallon, (1999, p.41) a afetividade é a teoria da emoção e do caráter em sua concepção a afetividade tem o papel imprescindível, no processo de desenvolvimento da personalidade, e este por sua vez, se constitui sobre alternância dos domínios funcionais, que na verdade é a primeira etapa por onde a criança percorre, também ressalta que o nascimento da afetividade é anterior a inteligência.

O afeto é o elemento principal da afetividade ele permite a criança, construir a noção daquilo que almeja noções sobre o objeto, pessoa e situações. A partir daí as crianças constrói relações afetivas com o que foi descoberto e atribui, seus valores e significados.

Com a afetividade se relacionam segundo as manifestações psíquicas mais precoces das crianças. Ela está automaticamente ligada às suas necessidades e automatismo alimentares, que são quase imediatamente consecutivos ao nascimento. Parece difícil não fazer depender da afetividade como expressão de indisposição ou de bem-estar, o primeiro comportamento muscular e vocal do lactante. as gesticulações o que também normalmente se entrega parece ser ao mesmo tempo sinal e fonte de prazer. Ela tem ai a sua base própria céptica, como nas funções vísceras, especialmente aos tubos digestivos a sua interoceptivas. (WALLON apud ALMEIDA, 1994, p. 117)

As primeiras trocas afetivas vêm da mãe e filho, os cuidados básicos oferecidos e as ações e relações entre criança e meio de convívio, vão moldado o seu 
comportamento e essas vivencias, serão posteriormente transferidas ao meio social permitindo ou não sua adaptação. O desenvolvimento humano é um processo construtivo, que se dá através das interações contínuas do sujeito (homem) com os objetos de conhecimento (mundo físico ou seres humanos). (PIAGET, 1998, p. 26)

Piaget (1988), destaca a unidade entre a afetividade e a cognição, defendendo a necessidade de investigar a interferência da afetividade em nossas ações cotidianas. Para ele os conhecimentos são construídos na iteração entre emoção e razão, na medida em que defende a existência de uma relação direta entre o conhecimento e a afetividade. É esta ligação que pretendemos analisar e que utilizaremos para abordar experiências educativas.

Já Wallon (1993) definiu a teoria da afetividade como da emoção e do caráter. A afetividade para ele tem o papel fundamental no desenvolvimento da personalidade, pois é o primeiro domínio funcional percorrido pela criança. O recém-nascido e a criança, no seu primeiro ano de vida, utilizam gestos e expressões carregada de significados afetivos, anteriores a inteligência. (WALLON, 1993)

NA teoria piagetiana, a afetividade impulsiona o desenvolvimento cognitivo e se fortalece com as estruturas construídas e a direção da atividade intelectual. Para PIAGET (1976, 1989), o desenvolvimento mental evolui até atingir um equilíbrio final obtido a partir de um processo de equilibração progressiva. Assim também é o desenvolvimento afetivo tende a uma maior equilibração com o aumento da idade. $O$ desenvolvimento das funções da inteligência não acontece de forma, compartimentada ou separadamente, mas juntas indissociáveis e complementares, (PIAGET, 1974, p. 24).

Segundo Wallon (1979), a cognição é vista como parte da pessoa completa que só pode ser compreendida integrada a ela, cujo desenvolvimento se da a partir das condições orgânicas da espécie, e é resultado da interação entre seu organismo e o meio, predominante o social. Assim o desenvolvimento é condicionado tanto pela maturação orgânica como pelo exercício funcional propiciado pelo meio. 
Observa se que tanto Piaget como Wallon, defendem em ambas teorias que o desenvolvimento afetivo e cognitivo da criança vem do meio de convívio com a família. Então a família se torna a base de todos os desenvolvimentos da criança, pois é a partir dela que a criança forma sua personalidade. Sendo assim fica prova por Piaget e Wallon que a família favorece o desenvolvimento tanto afetivo como cognitivo da criança.

\subsection{A IMPORTANCIA DA ESCOLA NA FORMAÇÃO DO CIDADÃO}

As escolas institucionalizadas foram criadas para o desenvolvimento da sociedade, é nela onde todos aprendem uma diversidade de conhecimentos e competências, por esse motivo a escola desempenha o papel fundamental e insubstituível na consolidação das sociedades democráticas e em princípios sociais e éticos.

A principal finalidade da escola é a de inserir as crianças, adolescentes e jovens em um círculo social com a transferência de conhecimento, na escola a criança aprende a socialização nos primeiros anos escolares, pois são passados os conceitos de convívio em sociedade.

A socialização é necessária para compreendermos como funciona a vida desde cedo, saber seus direitos e deveres, e o valor de respeito ao próximo. O professor tem o papel de guia desse caminho a ser percorrido que é a vida escolar, mas ao mesmo tempo cabe a ele também a árdua tarefa de transmitir o conhecimento, a escola tem o papel de ensinar os alunos a buscar o conhecimento, mas cabe aos pais a tarefa de educar os filhos de acordo com o comportamento social. A escola funciona assim como espaço de socialização e transmissão de conhecimento. 


\subsection{A EDUCAÇÃO DOMICILIAR COMO PROPOSTA DE EDUCAÇÃO}

As famílias que aderem a esse novo modelo de educação especulam que o ensino oferece um ambiente de aprendizado diferente do encontrado nas escolas, para essas famílias a escola acaba inibindo a criança e sua criatividade, desestimulando o interesse da criança pelo aprendizado, os pais defendem que na educação domiciliar os filhos não estão sujeitos a sofrerem algum tipo de violência e terão educação de qualidade. [...] se toda pessoa tem direito a educação, é evidente que os pais também, possuem o direito de serem, senão educados, ao menos informados no tocante á melhor educação a ser proporcionada a seus filhos. (PIAGET, 2007, p.50)

As leis defendem que no ensino domiciliar não existe a "socialização", e partem do pressuposto que socialização é a criança interagir com outras crianças. Entendese que pode haver o entendimento de socialização a partir do momento em que há interação com outras pessoas sejam elas, pais, tutores, responsáveis, professores contratados, irmãos, existe sim a socialização, e fora esse momento, considera-se que no momento em que não está estudando as crianças do ensino domiciliar estão interagindo com outras pessoas : num momento de passeio, participando de aulas de dança, futebol, brincando em um parquinho entre outras coisas.

O ensino não fica por conta apenas dos pais, há sim pais que se comprometem em eles mesmos ensinar seus filhos ,como também há os que contratam professores particulares para fazer essa educação, todos seguem um roteiro curricular, até por que no momento que se passa a ser transmissor de conhecimento, você tem que buscar informações para se preparar para isso. Na maioria das vezes a educação domiciliar acontece por que a família não concorda com o ensino da escola e nem com os valores que transmite, juntando com o desejo de participar da educação dos filhos, segundo essas famílias sempre é possível oferecer uma formação que vá além da escola, na educação domiciliar a criança tem a possibilidade de aprender e brincar praticando a socialização com outras crianças e criando uma motivação pelo aprendizado, em um processo de educação ativa onde existe a possibilidade real de ser sujeito e promotor do seu próprio conhecimento e aprendizagem. (BESHONER et al,1981). 


\subsection{MÉTODOS UTILIZADOS NA EDUCAÇÃO DOMICILIAR}

O primeiro ponto a ser destacado é a diferença entre a "unschooling" e "homescholing". Na unschooling os pais não desenvolvem formas estruturadas de ensino, no caso metodologias, pois defendem a tese que as crianças têm que aprender com o mundo ou seja eles escolhem o que estudar e como estudar, unschooling se posiciona totalmente contra a escola.

Unschooling , para mim , significa aprender o que a pessoa quer, quando quer , da forma como quer,onde quiser, e pela razão que for, o aprendizado é direto; ajudantes ou facilitadores, são procurado a medida que a pessoa quiser" (GRIFFITH.1998, p.3 tradução nossa).

Já no homeschooling, existe um certo padrão no ensino, com métodos bons e ruins acreditando que a criança tem sim sua subjetividade, mais isso não a torna independente a ponto de querer apenas o que quiser e como quiser tem que seguir uma metodologia imposta pelos educadores

A educação domiciliar capaz de oferecer uma variedade de método, para que se possa ministrar em casa com facilidade de mudança na forma como se ensina a educação a uma criança. Os pais da educação doméstica são ao mesmo tempo pesquisadores pois, sempre estão buscando novos métodos de aprendizado , pois visão uma educação com qualidade para seus filhos, eles assumem a responsabilidade pelo aprendizado dos filhos onde são capazes de oferecer um ensino padronizado, com acompanhamento ou também contratam profissionais que educarão seus filhos e que estejam a sua disposição.

Um dos principais objetivos do homeschoolig, é a habilidade de adaptar a educação de acordo com as necessidades de cada estudante e a possibilidade de trabalhar com a criança de forma mais individualizada. A maioria das escolas tem um professor para um grupo de alunos, o que não permite alunos o que não permite que as necessidades educacionais de cada 
criança sejam realmente reconhecidas. Mas muitas famílias que educam em casa usam uma forma de abordagem que segue muito o estilo escopo, sequência e materiais utilizados nas instituições de ensino tradicionais. Outras famílias escolhem abordagem padronizadas de modelo da educação clássica, incorporando lógica latim e o pensamento crítico. (SCHWARZER, 2008,p.10 tradução nossa)

As crianças são observadas a cada ciclo para saber como anda o desenvolvimento educacional, com isso os pais constroem um certo cronograma a ser seguido ao longo do ano, baseado nos conteúdos que a criança deve aprender neste período. Alguns desses métodos são, os livros didáticos, feitos para a educação domiciliar importados dos EUA, e outros são materiais didático brasileiro feitos para as escolas institucionalizadas. Os pais que têm uma renda alta preferem recorrer ao EUA onde encontram grandes métodos de ensino como planos curriculares, material pedagógico e cooperativas de famílias que se unem para ajudar uma as outras com a troca de conhecimento.

Sempre que se trata da educação domiciliar, uma questão é levantada e o problema da socialização da criança. Análises comprovam que as crianças educadas em casa conseguem se desenvolver e socializar normalmente com outras crianças, por meios de convívio.

As crianças educadas em casa estão tomando parte de rotinas diárias de suas comunidades. Elas certamente não estão isoladas, na verdade estão associadas com todo tipo de pessoas. As crianças educadas em casa estão adquirindo as regras de conhecimento e o sistema de crenças e atitudes que necessitam. Elas têm boa auto estima e estão propensas a demonstrar menos problema de comportamento do que outras crianças. (MEDLIN, 2000, p.17 apud VIEIRA, 2012,p.15).

Considera-se aqui que os pais e responsáveis tem total capacidade de educá-la em casa, pois possuem o mero conhecimento para a prática do ensino dos filhos, buscando um novo meio de sair do padrão de uma sala de aula. Já que todos os momentos de nossa vida podem ser de aprendizado. 


\section{4 AVANÇOS DA PROPOSTA DE EDUCAÇÃO DOMICILIAR}

A cada dia cresce o número de pessoas que tomam conhecimento do que seja esse tipo de educação, alguns por curiosidade, outros que vêem a possibilidade de uma educação melhor, mais personalizada e especifica. O método não é uma forma contrária à escola, mas um modelo que depende da realidade de cada família, de suas estruturas e seus objetivos. Além do mais os pais tem a oportunidade de ficar atentos a possíveis problemas de aprendizado e como já foi dito acima, especificar, personalizar e não apenas normatizar e condicionar como faz a educação escolar tradicional.

O Brasil possui cerca de três mil famílias que preferem ensinar as crianças em casa, confira o gráfico da evolução de famílias que já adotaram esse modelo de educação em cinco anos.

Esse gráfico mostra claramente o número de famílias e cidades que já aderiram ao ensino domiciliar. Como podemos ver a quantidade de adeptos quase triplicou de 2011 até 2016. Esse é o gráfico mais recente de lá até aqui, presume-se que esse número possa ter aumentado. 


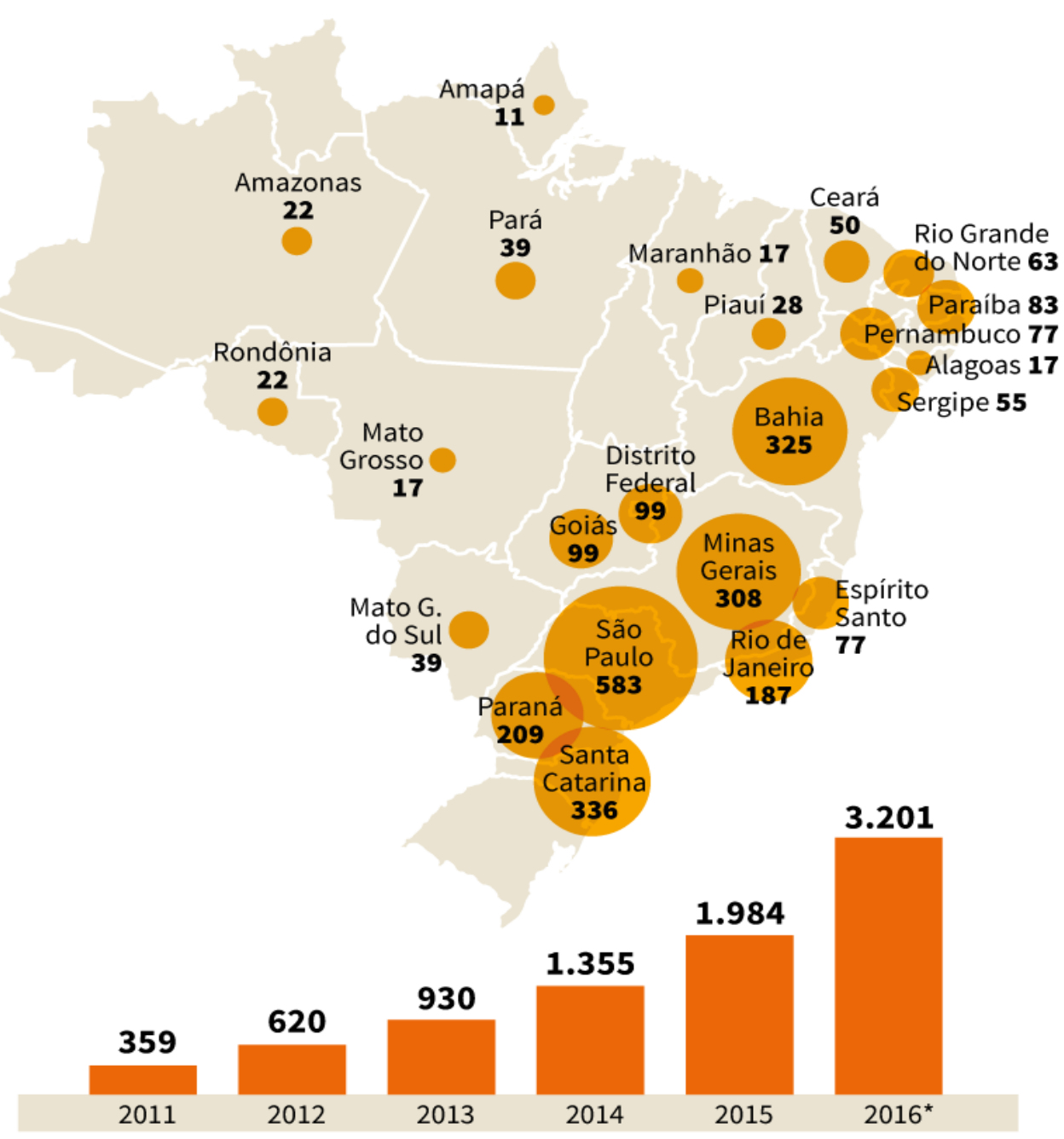

\section{CONSIDERAÇÕS FINAIS}

Este trabalho visou definir educação domiciliar ou homeschooling , buscando mostrar suas mostrar suas características, legalidade e sua importância no desenvolvimento educacional das crianças às quais os pais optam por esse modelo de educação. Apesar de não haverem pesquisas mais contundentes sobre o tema, ou estudos de caso especificamente tratando dele, onde sejam avaliadas as crianças submetidas a esse tipo de educação, teoricamente entende-se que a educação domiciliar, não afeta em nada o desenvolvimento educacional da criança, como alega a legislação, pelo contrário foi constatado avanços em todas as áreas de 
desenvolvimento dessas crianças, adolescente e jovens que pratica o homeschooling termo inglês como também é conhecido.

Entende-se aqui que tanto a educação institucionalizada aquela praticada na escola, quanto a educação domiciliar tem o mesmo objetivo, educar essas crianças instruindo a criança em busca do conhecimento. Com isso o artigo tenta apresentar a questão da educação domiciliar para aqueles que ainda não o conhecem enquanto discussão teórica, assim como demonstrar que a opção desse método não é algo que está alheio ou distante da nossa realidade.

Presume-se também que embora contestada pela lei, a educação domiciliar não irá simplesmente se extinguir no Brasil, e, provavelmente será uma questão de tempo até que ela seja legalizada no país. Sendo assim reflete-se a necessidade da regulamentação desta modalidade de ensino, trazendo para a sociedade em questão a segurança jurídica e o exercício de direito de escolha daqueles que veem na educação domiciliar, uma forma mais humana e condizente de educar os filhos. 


\section{REFERENCIAS}

ALLIE-CARSON, Jayn. "Estrutura e Padrões de Interação das Famílias Escolares Domiciliares." Pesquisador a Home School 6, no 3 (1990): 11-18.

ALMEIDA. Laurinda Ramalho de. Wallon e a Educação. in: Henri Wallon- Psicologia e Educação: São Paulo: Loyola.2000.

Beshoner, E. Alice Law. "Educação domiciliar na América: direitos dos pais reafirmados." UMKC Review 49, № 2 (1981): 191-206.

BRASIL. Lei de Diretrizes e Bases da Educação Nacional (LDB) Lei n 9394/96

BRASIL.Constituição da Republica Federativa.40 ed. São Paulo: Saraiva 2007.

Dumas, Tanya K., Sean Gates e Deborah R. Schwarzer. "Evidência para o ensino domiciliar: Análise Constitucional à Luz da Pesquisa em Ciências Sociais." Revisão da Lei Widener 16, no 1 (2010): 63-87.

GRIFFITH, Mary. The Unschooling Handbook: How to use the whole world as your child' classroom .2. ed. Now York : Three Rivers Press, 1998.

PIAGET,J.Pscologia da inteligência. Rio de Janeiro:editora fundo de cultura, 1961.

A Relação da afetividade com a inteligência no desenvolvimento mental da criança.vol 26 n3, 1962.

J. A equilibração das estruturas cognitivas.Rio de Janeiro:editora zahar 1983.

Seis Estudos de Psicologia.Rio de Janeiro:Forense Universitaria,1989.

Para onde vai a educação? Tradução de Ivete Braga, $14^{\circ}$ edição Rio de Janeiro:José Olimpio,1998.

\& INHELDER, B.. A psicologia da criança. Rio de Janeiro: Bertrand Brasil, 1999. 
TORRES, Sueli. Uma função Social da Escola. Em www.fundaçaõromi.org.br/homesite/news.asp?news=775.2008 Acesso em 27 de janeiro de 2018.

WALLON, Henri. Psicologia e Educação da Infância.Lisboa: Estampo.1975. . Do acto ao pensamento . Lisboa : Morais. 1979.

VIEIRA, André de Holanda Padilha. Escola ? não obrigdo: um retrato da homschooling no Brasil. 2012. 76Fmanografia (bacharelado em ciências sociais), universidade de Brasilia, Brasilia 2012 . Disponível em http://bdm.unb.br/handle/10483/3946?mode=simple acesso em 27 jan 2018.

https://oglobo.globo.com/sociedade/stf-vai-definir-se-familias-podem-optar-peloensino-domiciliar-21802711 